\title{
Prevalence of Helicobacter Pylori Infection in Patients with Upper Gastrointestinal Bleeding
}

\author{
Mustafa Mohamed Abdulateef*, Rushdi Abdulhameed Abdulameer, Laith Hikmet Muhsun
}

Al-Kindy Teaching Hospital, Baghdad, Iraq

Email address:

troysolder.mm@gmail.com (M. M. Abdulateef)

${ }^{*}$ Corresponding author

\section{To cite this article:}

Mustafa Mohamed Abdulateef, Rushdi Abdulhameed Abdulameer, Laith Hikmet Muhsun. Prevalence of Helicobacter Pylori Infection in Patients with Upper Gastrointestinal Bleeding. European Journal of Preventive Medicine. Vol. 7, No. 6, 2019, pp. 123-129.

doi: 10.11648/j.ejpm.20190706.16

Received: August 2, 2019; Accepted: November 20, 2019; Published: December 4, 2019

\begin{abstract}
Helicobacter pylori is one of the most common chronic bacterial infections in humans, with more than $50 \%$ of the world's population infected with these bacteria It is a micro-aerophilic, slow-growing, gram-negative spiral bacterium that colonizes the mucous lining of the human stomach. Warren and Marshall first cultured and identified the organism as Campylobacter pylori in 1982. In 1989, it was renamed and recognized to be associated closely with antral gastritis (gastric and duodenal ulcers in adults and children). Further evidence supported a link between chronic gastritis of Helicobacter pylori (H. pylori) infection in adults and malignancy, specifically gastric lymphoma and adenocarcinoma. Infection with this bacterium has been identified as a cause of gastritis, peptic ulcer disease, and gastric mucosa-associated lymphoid tissue lymphoma. Globally, the prevalence of H. pylori-related infection is high compared to any other infectious diseases, and the rate of prevalence much higher in developing countries than in developed nations.
\end{abstract}

Keywords: Helicopter Pylori Infection, Upper Gastrointestinal Bleeding, Non-steroid Anti-inflammatory Drugs, Oesophagio-Gastro-duodenoscopy

\section{Introduction}

Helicobacter pylori is one of the most common chronic bacterial infections in humans, with more than $50 \%$ of the world's population infected with these bacteria [1]. Genetic sequence analysis has proposed that humans have been infected with $\mathrm{H}$ pylori for more than 58, 000 years [2]. While $\mathrm{H}$ pylori have been demonstrated worldwide in individuals of all ages, infection is commonly acquired at an earlier age in Developing countries as compared with industrialized nations [3-4]. In older children and adults, infection persists so that in the developing areas of the world the overall $\mathrm{H}$ pylori prevalence can reach more than $80 \%$ in individuals older than 50 year [4]. H pylori are unique bacteria that are ideally suited to live in the acidic environment of the human stomach [1]. Person-to-person transmission of bacteria from fecal-oral, oral-oral, or gastric-oral exposure seems the most probable explanation for infection [4-5]. Especially in developing countries, contaminated water might serve as an environmental source of bacteria because the organism can remain viable for several days in water [6]. Iatrogenic infection has occurred during the use of a variety of inadequately disinfected gastric devices, endoscopes, and endoscopic accessories. ${ }^{(4)}$ Gastroenterologists and nurses appear to be at greater risk for acquiring $\mathrm{H}$ pylori, presumably because of occupational contact with infected gastric secretions [7], although this is less likely to occur when universal precautions for infection control in the health care setting are strictly enforced.

The ultimate clinical manifestations of $\mathrm{H}$ pylori infection include gastric and duodenal ulcers, gastric marginal zone B-cell lymphoma (formally MALT lymphoma), and gastric adenocarcinoma. Eradicating the infection prevents recurrence and ulcer complications such as bleeding or perforation [8-9]. However, most infected individuals remain asymptomatic, despite developing chronic histologic gastritis.

Acute upper gastrointestinal bleeding (UGIB) is also a serious clinical problem. UGIB has been associated with a mortality rate of approximately $5 \%$ to $10 \%$ [10-11]. A bleeding peptic ulcer is the most common cause of UGIB [12]. 
Diagnostic testing for $\mathrm{H}$ pylori infection can be divided into endoscopic and non-endoscopic methods. The appropriate method for testing depends on the clinical situation, test availability, and cost. In many instances, the choice of which test to use is determined by whether endoscopy is indicated on a clinical basis. Furthermore, the recent use of antibiotics or PPIs can affect the results of certain $H$ pylori tests [13], and thereby influence the choice of which test to use.

During Oesophagio-Gastro-Duodenoscopy (OGD), there are three methods to identify the organism in a gastric biopsy specimen: rapid urease test, histology, and culture. The choice of method depends on the clinical situation, cost, and test accuracy [14]. In general, in each case, 1 or 2 biopsies should be obtained from both the antrum and corpus. Guidelines propose initially using the rapid urease test because the method is efficient, relatively inexpensive, and generally accurate [14-15]. Test results are often positive within minutes to hours. The sensitivity and specificity of the rapid urease tests are $90 \%$ to $95 \%$ and $95 \%$ to $100 \%$, respectively [16-17]. Accuracy can be negatively affected by blood in the stomach [18] or by current or recent use of certain medications such as antibiotics, bismuth containing compounds, or acid anti-secretory drugs, especially PPIs [19]. Therefore, a negative urease test does not necessarily exclude $\mathrm{H}$. pylori infection in an individual taking anti-secretory medication, a common scenario in patients referred for EGD.

Histologic examination had been considered the gold standard for identifying infection, with reported sensitivity and specificity as high as $95 \%$ and $98 \%$, respectively [20]. However, the distribution and density of organisms can vary within the stomach, resulting in sampling error, particularly in patients taking anti-secretory medications $[14,16]$. Histology is the optimal method for the detection of H. pylori associated premalignant lesions (multifocal atrophic gastritis, intestinal metaplasia, dysplasia) [16].

H. pylori are difficult to culture because the organism is fastidious, slow growing, and requires specialized media and growth environment [16, 21]. Serology, the most popular noninvasive test in clinical practice, is used for its convenience and expense. Infection incites a systemic immune response, and enzyme-linked immunosorbent assay (ELISA) technology can detect IgG antibodies to a variety of bacterial antigens in serum samples [16, 21]. Although serology is inexpensive, noninvasive, and ideally suited to a primary care setting, the prevalence of $\mathrm{H}$. pylori in the population being tested influences its accuracy [14]. The sensitivity of serology is generally quite high $(90 \%$ to $100 \%)$, but its specificity is variable $(76 \%$ to $96 \%)$, especially if prevalence of $\mathrm{H}$. pylori is low. Use of another test, such as a stool antigen or urea breath test, is recommended in low prevalence populations. In most instances, serology remains positive for months to years after successful treatment of infection. This "serologic scar" effectively precludes use of serology to confirm bacterial eradication after treatment, a practice that is unfortunately still quite common in the primary care setting, even though better tests to confirm eradication are available. The urea breath test (UBT) detects active H. pylori infection and is useful for making the primary diagnosis and for documenting successful treatment [14]. The specificity of UBT is better than $95 \%[14,16]$, making false-positive results uncommon. The sensitivity of the test is $88 \%$ to $95 \%$, with false-negative results reported in patients taking anti-secretory therapy such as PPIs [14, 19], bismuth, or antibiotics.

An immunoassay that detects bacterial antigens in stool of infected patients is the other principal noninvasive modality to diagnose active $\mathrm{H}$. pyloriS infection and confirm eradication following treatment. Overall sensitivity and specificity of the stool test are comparable to the UBT (94\% and $97 \%$, respectively) $[14,17,21]$. The sensitivity of stool testing is also reduced by PPIs, bismuth, and antibiotics,

Recommended $\mathrm{H}$. pylori treatment regimens generally include two antibiotics and a PPI for 10 to 14 days [13, 23]. Attempts to simplify regimens or shorten treatment duration reduce effectiveness. Treatment success rates can vary among countries and regionally within countries, related to antibiotic resistance and local ecology [22-23]. Standard antibiotic dosages are used in most of the treatment regimens: clarithromycin $500 \mathrm{mg}$, amoxicillin $1 \mathrm{~g}$, metronidazole 500 $\mathrm{mg}$, tinidazole $500 \mathrm{mg}$, tetracycline $500 \mathrm{mg}$ and levofloxacin $500 \mathrm{mg}$. PPIs are administered twice daily at standard doses: omeprazole $20 \mathrm{mg}$, lansoprazole $30 \mathrm{mg}$, pantoprazole $40 \mathrm{mg}$, rabeprazole $20 \mathrm{mg}$, esomeprazole $40 \mathrm{mg}$, or dexlanzoprazole $30 \mathrm{mg}$. In general, there are no significant differences in eradication efficacy noted between PPIs. High-dose H2RAs may be substituted for PPIs in the event of allergy or adverse effects, although PPIs are generally recommended. The dosages of the various formulations of bismuth will depend upon regional availability (e.g., bismuth subsalicylate $524 \mathrm{mg}$ vs. bismuth subcitrate $420 \mathrm{mg}$ ).

Triple therapy, composed of clarithromycin, amoxicillin, and a PPI given for 10 to 14 days, is currently the most common initial treatment for H. pylori, supported by several international guidelines. Triple therapy consistently cures over $80 \%$ of infections if organisms are sensitive to clarithromycin and a 10- to 14-day regimen is used [24]. Clarithromycin resistance consistently affects the efficacy of triple therapy, which has generated interest in other regimens. Alternatives to triple therapy should be considered in regions of documented high (i.e., $>15 \%$ to $20 \%$ ) clarithromycin resistance $[15,27]$. Other regimens may also be appropriate for specific patient groups. For example, H. pylori-infected patients with lung disease who have been treated repeatedly with macrolides are likely to have clarithromycin-resistant Hp. Metronidazole can be substituted for either amoxicillin or clarithromycin, which is appropriate for penicillin-allergic or macrolide-intolerant individuals [13, 22, 26-27].

A 10-day sequential therapy regimen consists of a PPI and amoxicillin given twice daily for 5 days, followed for the next 5 days by a PPI, clarithromycin, and a nitroimidazole (tinidazole or metronidazole), each given twice daily. This sequential approach is based upon the premise that initial amoxicillin treatment may increase bacterial cell wall permeability and thereby improve the efficacy of the subsequent antibiotics in eradicating $\mathrm{H}$. pylori. 
Bismuth-based quadruple therapy, which combines a bismuth salt, metronidazole, and tetracycline (each given 4 times daily), with a twice-daily PPI for 2 weeks, was one of the first therapies used to treat H. pylori. Quadruple therapy is useful as first-line therapy in certain clinical situations (penicillin allergy, high probability of clarithromycin resistance) and also serves as one of the primary retreatment schemes. Although quadruple therapy is effective $(>80 \%$ eradication), the number of daily pills and associated frequent minor adverse effects negatively affect tolerability and compliance [13-22, 26-27].

A number of non-bismuth-based quadruple therapy regimens have been studied. The most common are the concomitant therapy regimens, which represent a variation on sequential therapy and are based either on clarithromycin or levofloxacin. Clarithromycin-based concomitant therapy consists of a twice-daily regimen of a PPI, clarithromycin, amoxicillin, and a nitroimidazole (metronidazole or tinidazole) for 5 to 10 days. Eradication rates range between $63 \%$ and $95 \%$, and treatment for 10 days has better efficacy [28]. Levofloxacin-based concomitant therapy provides an alternative approach for patients with macrolide allergy, probable clarithromycin resistance, and/or treatment failure. In a European study of levofloxacin-based regimens, a 5-day concomitant regimen was non-inferior to the 10-day regimen, with eradication rates of $92 \%$ and $93 \%$, respectively [29].

\section{Patients and Methods}

The aim of this study to estimate the prevalence of $H$. Pylori infection in adult patients with upper gastrointestinal bleeding who underwent upper Oesophagio-Gastro-Duodenoscopy (OGD).

This cross-sectional study was conducted at the GIT department of AL-Kindy teaching hospital from February 2015 to January 2016. Consecutive 70 patients ( $\geq 16$ year old) with upper GIT bleeding symptoms (hematemesis or coffee ground vomiting, melena or hematochezia) who presented to out -patient medical clinic or admitted to hospital or referred to the endoscope unit were enrolled in the study.

A questioner included patient's age, gender, symptom of presentation, history of comorbid disease, bleeding tendency, history of previous GIT bleeding, drug history (NSAIDs, Antiplatelet, and Anticoagulants), alcoholism. Physical examination looking for vital signs. Lab investigations to find out hemoglobin level, renal function and liver function tests were done.

After hemodynamic stabilization Upper GI endoscopy was performed by experienced gastroenterologist using video endoscope OLYMPUS-LUCERA CV-260 series for all patients. During endoscope the esophagus, stomach and duodenum were all visualized and all mucosal changes were noticed and registered.

Gastric biopsies were obtained during endoscopy after successful hemostasis if needed. Biopsies specimens were taken from the antrum, gastric body and incisura to search for H. pylori infection. All Biopsies that are taken during endoscope are placed in $10 \%$ formalin then send for histological examination. Sections were stained with Hematoxylin and Eosin stain and examined by an experienced histopathologist. Inclusion criteria: Any patient more than 16 years old of both sex who presented with any of the UGIT bleeding symptoms.

Exclusion criteria: None of the patients selected were on antibiotic treatment for the last 4 weeks or PPI in the last 2 weeks and $\mathrm{H} 2$ receptor antagonist in the last 2 days before endoscopy in order to avoid false negative H. pylori results, history of previous upper GI surgery, decompensated liver disease, esophageal varices, end stage renal disease, bleeding disorder and Patients with history of upper GIT bleeding who received treatment of $\mathrm{H}$. pylori eradication.

Data were introduced to PC, SPSS version 22 statistical software program was used in statistical analysis, two samples t-test and Chi square tests were used to show significant differences and associations between related variables, $\mathrm{P}$-value $\leq 0.05$ were considered as significant.

Ethical approval of scientific committee in Iraqi Board of Medical Specialization (internal Medicine) was obtained and patient's verbal consents were approved after had been informed about the scientific purpose of the study and confidentiality of information.

\section{Results and Discussion}

During this study 70 patients suffering from UGITB were exposed to upper gastrointestinal endoscopies. The overall prevalence of $\mathrm{H}$. pylori infection in upper gastrointestinal bleeding patients was $n=48 / 70(68.5 \%)$. Age of patients range from 18-75 year (mean=43.51year, $\mathrm{SD}=14.94)$. Among all patients, $48(68.5 \%)$ were male and $22(31.5 \%)$ were females. Table 1 shows no significant difference between age distribution of male and female in patients with UGITB (P value $=0.98$ ).

Table 1. Distribution of UGITB according to gender and age.

\begin{tabular}{lllll}
\hline Gender & Mean of age & SD & $\boldsymbol{T}$ test & $\boldsymbol{P}$ value \\
\hline Male & 43.5 & 16.1 & & \\
Female & 43.5 & 12.5 & 0.02 & 0.98 \\
Total & 43.51 & 14.91 & & \\
\hline
\end{tabular}

The age distribution of $\mathrm{H}$. pylori positive was 43.8 year $(\mathrm{SD}=14.7)$ while the age distribution of the non $\mathrm{H}$. pylori was 43 year $(\mathrm{SD}=15.8)$ there is no significant difference $(\mathrm{PV}=0.85)$, see Table 2 .

Table 2. Distribution of UGITB according to age and H. pylori infection.

\begin{tabular}{lllll}
\hline H. pylori infection & Mean of age & SD & T test & P value \\
\hline Positive & 43.8 & 14.7 & -0.19 & \multirow{2}{*}{0.85} \\
Negative & 43 & 15.8 & & \\
\hline
\end{tabular}

The rate of the infection among male and female patients was nearly similar $(68.7 \%$ and $68.1 \%$ respectively) and there was no significant association $\left(\mathrm{X}^{2} 0.537, \mathrm{PV} 0.464\right)$, see Figure 1. 


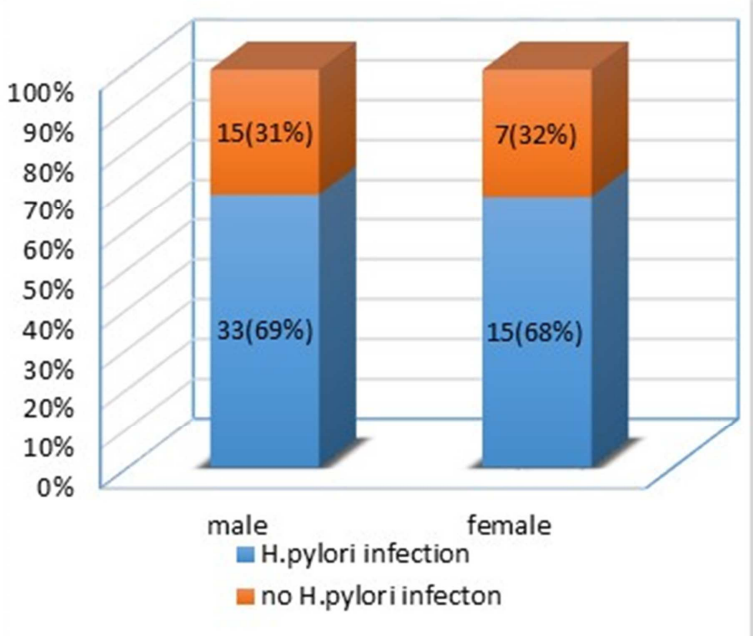

Figure 1. Distribution of UGITB according to gender and H. pylori infection.

The distribution of $\mathrm{H}$. pylori according to age group was: in $\leq 20$ year was $83.3 \%$, in $20-29$ year was $60 \%$, in $30-39$ year was $64.2 \%$, in $40-49$ year was $69.2 \%$, in $50-59$ year was $76.4 \%$, in $60-69$ year was $62.5 \%$ and in $\geq 70$ year was $50 \%$.

Figure 2 Showed that rate of $\mathrm{H}$. pylori infection was highest in the $\leq 20$ year age group (83.3\%) and lowest among those who are $\geq 70$ year age group $(50 \%)$. But this difference was statistically not significant $\left(\mathrm{X}^{2}=1.9, \mathrm{PV}=0.86\right)$.

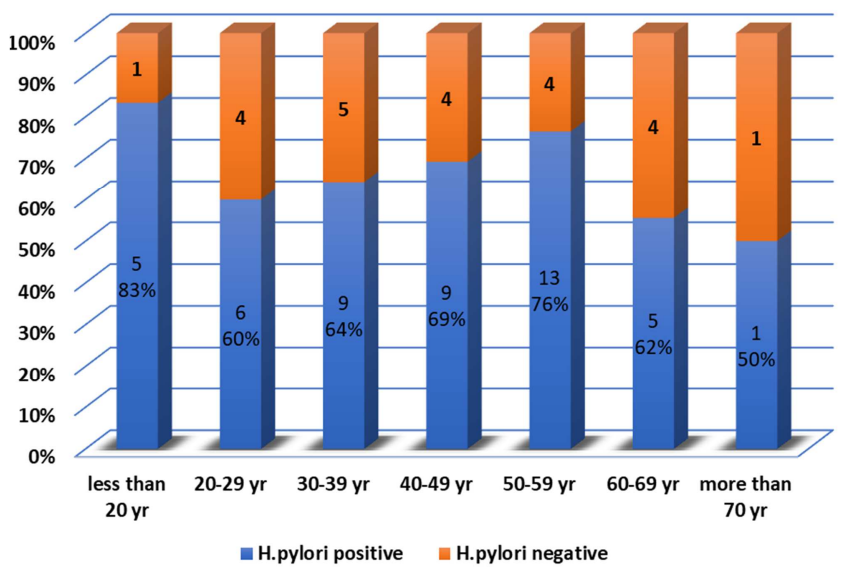

Figure 2. Distribution of UGITB according to age group and H. pylori infection.

The endoscopic finding was divided into duodenal ulcer $25 / 70(35.7 \%)$, gastric ulcer $16 / 70(22.8 \%)$, gastritis $15 / 70$ (12.8\%), duodenitis $9 / 70(12.8 \%)$, esophagitis $3 / 70(4.2 \%)$ and Mallory-Weiss tear 2/70 (2.8\%).

It was found that 21 out of $25(84 \%)$ of duodenal ulcer patients showed positive H. pylori infection while 13 patients out of $16(81.2 \%)$ of patients with gastric ulcers got $\mathrm{H}$. pylori infection and 14 out of $29(48.3 \%)$ of patients with other findings (gastritis, duodenitis. Esophagitis and Mallory-Weiss syndrom) had H. pylori infection. It's clear that there is positive association between duodenal ulcer and gastric ulcer with positive $\mathrm{H}$. pylori infection. The rate of $\mathrm{H}$. pylori infection in relation to the endoscopic finding is illustrated in Table 3.
Table 3. Distribution of UGITB patients according to endoscopic finding and H. pylori infection.

\begin{tabular}{lll}
\hline Endoscopic findings & H. pylori positive & H. pylori negative \\
\hline Duodenal ulcer & $21(84 \%)$ & $4(16 \%)$ \\
Gastric ulcer & $13(81 \%)$ & $3(19 \%)$ \\
Others & $14(48.3 \%)$ & $15(51.7 \%)$ \\
Duodenitis & 5 & 4 \\
Gastritis & 8 & 7 \\
Esophagitis & 1 & 2 \\
Mallory-Weiss tear & 0 & 2 \\
\hline
\end{tabular}

$\mathrm{X}^{2}=9.50, \mathrm{P}$ value $=.009$.

$\mathrm{X}^{2}$ was applied on data related to duodenal ulcer, gastric ulcer and others finding for purpose of statistical analysis.

Figure 3 showed that ulcerative lesions (duodenal or gastric ulcers) were predominant (58.5\%) of all UGITB patients.

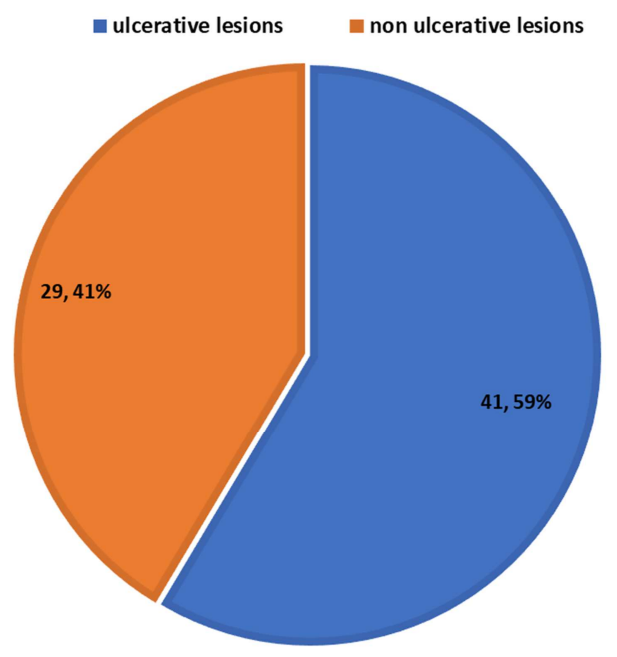

Figure 3. Distribution of UGITB according to endoscopic findings.

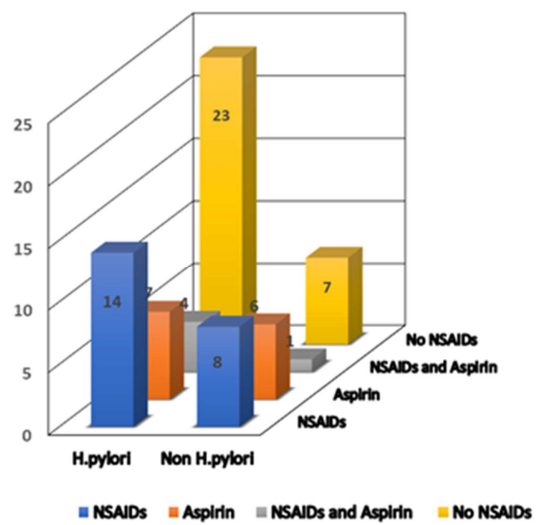

Figure 4. Distribution of UGITB according to NSAIDs consumption and H. pylori infection.

Forty patients $(57.1 \%)$ were have a history of chronic NSAIDs consumption particularly for pain relieve and Aspirin for primary or secondary prevention of cardio vascular disease. 25 patients $(52 \%)$ of $\mathrm{H}$. pylori infection were taking NSAIDs and/or Aspirin, while 15 patients $(68 \%)$ of non H. pylori patients were taking NSAIDs and/or Aspirin, see Figure 4. There was no significant association between NSAIDs consumption and UGITB among those who were H. pylori 
infection positive or not. $\mathrm{X}^{2=} 1.6, \mathrm{PV}=0.206$.

For more details Figure 4 showed that 22 patients consumed only NSAIDs before their bleeding events, among them 14 (63.6\%) had positive histology of H. pylori, 13 patients consume only Aspirin 100mg, 7 (53.8\%) of them had positive result of $\mathrm{H}$. pylori and 5 patients consume both NSAIDs and Aspirin 4 of them (80\%) had positive $\mathrm{H}$. pylori infection.

The prevalence of $\mathrm{H}$. pylori infection reported in healthy persons without gastrointestinal symptoms among different studies ranges from $11 \%$ to $69 \%$ with some of the variability that depending on different factors like geography, age, ethnicity and socioeconomic factors - low in developed countries and higher in developing countries [30-31]. Other studies show the prevalence of $\mathrm{H}$. pylori in symptomatic patients (postprandial fullness, early satiation, epigastric pain, epigastric burning and bloating, nausea, vomiting and UGITB symptoms) ranges from $60 \%$ to $80 \%$ [32], and in some studies up to $90 \%$ [33].

This study show prevalence of $\mathrm{H}$. pylori infection in patients with UGIT bleeding was $68.5 \%$ (48/70), the high prevalence was probably because the study was done among only symptomatic patients (UGITB symptoms). We found the percentage of the ulcerative lesions (gastric and duodenal) in this study was $58.5 \%(41 / 70)$ and the prevalence of $\mathrm{H}$. pylori was in duodenal ulcer $84 \%(21 / 25)$ and in gastric ulcer $81.2 \%$ $(13 / 16)$. We compared our results with other studies which show nearly same findings. Dixon MF reported a prevalence rate of $\mathrm{H}$. pylori of $93 \%$ for patients with duodenal ulcer and $80 \%$ for patients with gastric ulcer [34]. Zhang $\mathrm{C}$ et al also found the prevalence rate of $\mathrm{H}$. pylori infection in cases of bleeding gastric ulcer was $80 \%$ which is nearly similar to our result [35]. Another study done by Okan A et al, in which 96 patients with bleeding ulcers (gastric and/or duodenal) investigated for $\mathrm{H}$. pylori infection and show a rate of $66.7 \%$ [36].

The incidence of $\mathrm{H}$. pylori infection in our study was highest in young age group of $\leq 20$ years $(83.3 \%)$ that probably reflects the acquisition of the infection during childhood. The study show there is no significant association between $\mathrm{H}$. pylori infection and the gender of the patients. Male predominance infection has shown in some studies done by Chong VH et al, Zhang C et al and Dhakhwa R et al. [37-39], whereas other studies done by Kawasaki $\mathrm{M}$ et al and Malaty $\mathrm{HM}$ et al, show no any gender difference as in our study [40-41].

The damage effect of $\mathrm{H}$. pylori infection on the gastrodudenal mucosa in association with NSAIDs consumption is unclear, some studies show either little or no effect [44-45].

In this study 40 patients in a percentage of (57.1\%) had a history of NSAIDs or Aspirin consumption who were not on treatment with PPI or antibiotics. Of them 25 patients (62.5\%) have H. pylori infection and $15(37.5 \%)$ were not. Direct comparison of patients with NSAIDs consumptions who were infected with $\mathrm{H}$. pylori and those who were not, show there is no significant association between NSAIDs consumption and H. pylori infection in UGITB and both act independently.
These observation were also reported by Laine et al, who found the percentage of $\mathrm{H}$. pylori infection $(53 \%)$ in patients with gastric ulcer who consume NSAIDs and $(83 \%)$ in patients without NSAIDs consumption [44].

\section{Conclusions}

The prevalence of $\mathrm{H}$. pylori infection diagnosed by histopathology in adult patients with UGIT bleeding was $68.5 \%$. The prevalence of $\mathrm{H}$. pylori infection showing no significant difference according to age and gender. Endoscopic finding show ulcerative lesion (gastric and duodenal ulcer) as a source of bleeding have the highest percentage in comparison with other lesions. The number of patients who had history of NSAIDs or Aspirin consumption were found $40 / 70$ with percentage of $57.1 \%$ among these patients $25 / 40(62.5 \%)$ found to have $\mathrm{H}$. pylori positive infection, with no significant association between NSAIDs consumption and $\mathrm{H}$. pylori infection in patients with UGIT bleeding.

\section{References}

[1] Peura DA, Crowe SE. Helicobacter pylori. In: Feldman M, Friedman LS, Brandt LJ, editors. Sleisenger and Fordtran's gastrointestinal and liver disease. 9th edition, Philadelphia: Saunders; 2010. p. 833-45.

[2] Linz B, Balloux F, Moodley Y, et al. An African origin for the intimate associationbetween humans and Helicobacter pylori. Nature 2007; 445 (7130): 915-8.

[3] Kivi M, Tindberg Y. Helicobacter pylori occurrence and transmission: a family affair? Scand J Infect Dis 2006; 38 (6/7): 407-17.

[4] Brown LM. Helicobacter pylori: epidemiology and routes of transmission. Epidemiol Rev 2000; 22 (2): 283-97.

[5] Amieva MR, El-Omar EM. Host-bacterial interactions in Helicobacter pylori infection. Gastroenterology 2008; 134 (1): 306-23.

[6] Bellack NR, Koehoorn MW, MacNab YC, et al. A conceptual model of water's role as a reservoir in Helicobacter pylori transmission: a review of the evidence. Epidemiol Infect 2006; 134 (3): 439-49.

[7] De Schryver AA, Van Hooste WL, Van Winckel MA, et al. Helicobacter pylori infection: a global occupational risk for healthcare workers? Int J Occup Environ Health 2004; 10 (4): 428-32.

[8] Behrman SW. Management of complicated peptic ulcer disease. Arch Surg 2005; 140 (2): 201-8.

[9] Labenz J, Borsch G. Role of Helicobacter pylori eradication in the prevention of peptic ulcer bleeding relapse. Digestion 1994; 55 (1): 19-23.

[10] Van Leerdam ME, Vreeburg EM, Rauws EA, et al. Acute upper GI bleeding: did anything change? Time trend analysis of incidence and outcome of acute upper GI bleeding between 1993/1994 and 2000. Am J. Gastroenterol 2003; 98 (7): 1494-9. 
[11] Rockall TA, Logan RF, Devlin HB, et al. Incidence of and mortality from acute upper gastrointestinal haemorrhage in the United Kingdom. Steering Committee and members of the National Audit of Acute Upper Gastrointestinal Haemorrhage. Clinical research ed. BMJ 1995; 311 (6999): 222-6.

[12] Elmunzer BJ, Young SD, Inadomi JM, et al. Systematic review of the predictors of recurrent hemorrhage after endoscopic hemostatic therapy for bleeding peptic ulcers. Am J Gastroenterol 2008; 103 (10): 2625-32 [quiz: 2633].

[13] Chey WD, Wong BC. American College of Gastroenterology guideline on the management of Helicobacter pylori infection. Am J Gastroenterol 2007; 102 (8): 1808-25.

[14] Lim, Lee Guan, Khek Yu Ho, J. B. So, C. J. Khor, Li Lin Lim, Pui Li Teoh, and Khay Guan Yeoh. "Diagnosis and treatment of Helicobacter pylori for peptic ulcer bleeding in clinical practice-factors associated with non-diagnosis and non-treatment, and diagnostic yield in various settings." The Turkish journal of gastroenterology: the official journal of Turkish Society of Gastroenterology 25, no. 1, 2014: 157-161.

[15] Malfertheiner P, Megraud F, O'Morain CA, et al. Management of Helicobacter pylori infection-The Maastricht IV/Florence Consensus Report. Gut 2012; 61: 646-64.

[16] Versalovic J. Helicobacter pylori. Pathology and diagnostic strategies. Am J Clin Pathol 2003; 119: 403-12.

[17] Midolo P, Marshall BJ. Accurate diagnosis of Helicobacter pylori. Urease tests. Gastroenterol Clin North Am 2000; 29: 871-8.

[18] Gisbert JP, Abraira V. Accuracy of Helicobacter pylori diagnostic tests in patients with bleeding peptic ulcer: A systematic review and meta-analysis. Am J Gastroenterol 2006; 101: 848-63.

[19] Gatta L, Vakil N, Ricci C, et al. Effect of proton pump inhibitors and antacid therapy on $13 \mathrm{C}$ urea breath tests and stool test for Helicobacter pylori infection. Am J Gastroenterol 2004; 99: 823-9.

[20] El-Zimaity HM. Accurate diagnosis of Helicobacter pylori with biopsy. Gastroenterol Clin North Am 2000; 29: 863-9.

[21] Megraud F, Lehours P. Helicobacter pylori detection and antimicrobial susceptibility testing. Clin Microbiol Rev 2007; 20: $280-322$.

[22] Vakil N, Megraud F. Eradication therapy for Helicobacter pylori. Gastroenterology 2007; 133: 985-1001.

[23] Megraud F, Coenen S, Versporten A, et al. Helicobacter pylori resistance to antibiotics in Europe and its relationship to antibiotic consumption. Gut 2013; 62: 3442.

[24] Greenberg ER, Anderson GL, Morgan DR, et al. 14-day triple, 5-day concomitant, and 10-day sequential therapies for Helicobacter pylori infection in seven Latin American sites: A randomised trial. Lancet 2011; 378: 507-14.

[25] Megraud F. H. pylori antibiotic resistance: Prevalence, importance, and advances in testing. Gut 2004; 53: 1374-84.

[26] Peura DA. Treatment of Helicobacter pylori infection. In: Wolfe MM, editor. Therapy of digestive disorders. Philadelphia: Elsevier; 2006. p 277.

[27] Malfertheiner P, Megraud F, O'Morain C, et al. Current concepts in the management of Helicobacter pylori infection: The Maastricht III Consensus Report. Gut 2007; 56: 772-81.
[28] Gisbert JP, Calvet X. Review article: Rifabutin in the treatment of refractory Helicobacter pylori infection. Aliment Pharmacol Ther 2012; 35: 209-21.

[29] Federico A, Nardone G, Gravina AG, et al. Efficacy of5-day levofloxacin-containing concomitant therapy in eradication of Helicobacter pylori infection. Gastroenterology 2012; 143: 55-61 e51; quiz e13-54.

[30] Megraud F. Epidemiology of Helicobacter pylori infection. In: Rathbone BK, Heatley RV, editors. Helicobacter pylori and gastroduodenal disease. London: Blackwell Scientific Publication; 1993. pp. 107-23.

[31] Veldhuyzen van zantel SJ. Do socioeconimicstatus, marital status and occupation influence the prevalence of Helicobacter pylori infection? Aliment Pharmacol Ther. 1995; 9 (Suppl 2): 41-4.

[32] Hossein Khedmat, MD, Reza Karbasi-Afshar, MD, Shahram Agah, MD, and Saeed Taheri, MD. Helicobacter pylori Infection in the general population: A Middle Eastern perspective. Caspian J Intern Med. 2013 Autumn; 4 (4): 745-753.

[33] Al-Makdad A. M., Al-Dholaee M. H, Thabet A. A. K, Al-Haimi M. A, Balfaqih O. S. and Al-Hadad A. M. Prevalence of Helicobacter Pylori Infection inYemeni Patients. University of Science and Technology YEMENI JOURNAL FOR MEDICAL SCIENCES-p. 36.

[34] Suchartlikitwong, Sakolwan, Kamolyut Lapumnuaypol, Rungsun Rerknimitr, and Duangporn Werawatganon. "Epidemiology of upper gastrointestinal bleeding and Helicobacter pylori infection: review of 3, 488 Thai patients." Asian Biomedicine 9, no. 1, 2015: 87-93.

[35] Zhang C, Yamada N, Wu YL, Wen M, Matsuhisa T, Matsukura $\mathrm{N}$. Comparison of Helicobacter pylori infection and gastric mucosal histological features of gastric ulcer patients with chronic gastritis patients. World J Gastroenterol. 2005; 11: 976-81.

[36] Okan A, Tankurt E, Aslan BU, et al. Relationship between non-steroidal anti-inflammatory drug use and Helicobacterpylori infection in bleeding or uncomplicated peptic ulcers: A case-control study. J Gastroenterol Hepatol. 2003; 18: 18-25.

[37] Chong VH, Lim KC, Rajendran N. Prevalence of active Helicobacter pylori infection among patients referred for endoscopy in Brunei Darussalam. Singapore Med J. 2008; 49: 42-6.

[38] Zhang C, Yamada N, Wu YL, Wen M, Matsuhisa T, Matsukura $\mathrm{N}$. Helicobacter pylori infection, glandular atrophy and intestinal metaplasia in superficial gastritis, gastric erosion, erosive gastritis, gastric ulcer and early gastric cancer. World $\mathrm{J}$ Gastroenterol. 2005; 11: 791-6.

[39] Dhakhwa R, Acharya IL, Shrestha HG, Joshi DM, Lama S, Lakhey M. Histopathologic study of chronic antral gastritis. J Nepal Health Res Counc. 2012; 10: 57-60.

[40] Kawasaki M, Kawasaki T, Ogaki T, Itoh K, Kobayashi S, Yoshimizu Y, et al. Seroprevalence of Helicobacter pylori infection in Nepal: Low prevalence in an isolated rural village. Eur J Gastroenterol Hepatol. 1998; 10: 47-50.

[41] Malaty HM, El-Kasabany A, Graham DY, Miller CC, Reddy SG, Srinivasan SR, et al. Age at acquisition of Helicobacter pylori infection: A follow-up study from infancy to adulthood. Lancet. 2002; 359: 931-5. 
[42] Aalykke C, Lauritsen JM, Hallas J, Reinholdt S, Krogfelt K, Lauritsen K. Helicobacter pylori and risk of ulcer bleeding among users of nonsteroidal anti-inflammatory drugs: a casecontrol study. Gastroenterology 1999; 116: 1305-9.

[43] Huang JQ, Lad RJ, Sridhar S, Sumanac K, Hunt RH. H. pylori infection increases the risk of non-steroidal anti-inflammatory drug (NSAID)-induced gastro-duodenal ulceration. Gastroenterology 1999; 116 (4 part 2): A192A192 (Abstract).

[44] Laine L, Marin-Sorensen M, Weinstein WM. Non-steroidal anti-inflammatory drug-associated gastric ulcers do not require Helicobacter pylori for their development. Am J Gastroenterol 1992; 87: 1398402. 